peer-reviewed manuscript, published as: Ganzevles, Jurgen; van Est, Rinie; Nentwich, Michael (2014) Embracing Variety: Introducing the Inclusive Modelling of (Parliamentary) Technology Assessment. Journal of Responsible Innovation, Bd. 1 (3), S. 292-313 .

\title{
Embracing Variety: Introducing the Inclusive Modelling of (Parliamentary) Technology Assessment
}

\section{Jurgen Ganzevles ${ }^{1}$}

Institute for Science, Innovation and Society (ISIS), Faculty of Science, Radboud University, PO box 9010 - partition 77, 6500 GL Nijmegen, the Netherlands, tel. +31 243653201

\section{Rinie van Est}

Rathenau Instituut, Royal Netherlands Academy of Arts and Sciences (KNAW), PO box 95366, 2509 CJ The Hague, the Netherlands, tel: +31 703421542

\section{Michael Nentwich}

Institute of Technology Assessment (ITA), Austrian Academy of Sciences, Strohgasse 45/5, 1030 Wien, Austria, tel. +43 1515816583

This work was supported by the European Union under Grant Agreement no. 266649, Parliaments and Civil Society in Technology Assessment (PACITA). 


\section{Acknowledgements}

We wish to thank two anonymous reviewers for their valuable comments on an earlier version of this paper. In addition, we thank all partners in the PACITA consortium for their contributions to the PACITA (2012) report, on which this article is largely based (in alphabetical order, with 2012 affiliations mentioned): Frédéric Adam (University College Cork), Zsigmond Attila (HAS-SEC), Mara Almeida (ITQB), Marianne Barland (NBT), Frans Brom (Rathenau Instituut), Danielle Bütschi (TA-SWISS), Zoya Damianova (ARC Fund), Pierre Delvenne (Spiral, Université de Liège), Ferran Domínguez (CAPCIT), Johan Evers (Instituut Samenleving \& Technologie), Emiliano Feresin (TA-SWISS), Jon Fixdal (NBT), Katalin Fodor (HAS-SEC), Ingrid Geesink (Rathenau Instituut), Lenka Hebakova (Technology Centre ASCR), Leonhard Hennen (ITAS-KIT), Anders Jacobi (DBT), Ádám Kégler (HASSEC), Edgaras Leichteris (KEF, Lithuania), Lars Klüver (DBT), Ventseslav Kozarev (ARC Fund), Belén López (FCRI), Geert Munnichs (Rathenau Instituut), Linda Nierling (ITAS-KIT), Paidi O’Reilly (University College Cork), Marie Paldam Folker (DBT), Walter Peissl (ITAOEAW), Benedikt Rosskamp (Spiral, Université de Liège) and Mahshid Sotoudeh (ITAOEAW). We also thank Jasper Deuten (Rathenau Instituut) for his useful comments on an early version of the work.

Furthermore, we thank David Cope (POST, United Kingdom), Theo Karapiperis (STOA, European Parliament), Timothy Persons (GAO, USA), Eric Szij (OPECST, France), Pierre Delvenne (Spiral, Université de Liège) and Paula Tiihonen (Committee of the Future, Finland) for providing us with additional information about Parliamentary TA organizations that were not examined in detail in the PACITA (2012) study.

Network building and research for the PACITA (2012) report are supported by the European Union under Grant Agreement no. 266649, Parliaments and Civil Society in Technology Assessment (PACITA). 


\section{Embracing Variety: Introducing the Inclusive Modelling of (Parliamentary) Technology}

Assessment

\section{Introduction}

The notion of responsible innovation (RI) politically frames, enables and constrains contemporary discourse on how to properly enact a democratic governance of innovation. Von Schomberg (2012) provides an often-cited working definition, which explains that RI: (1) aims to achieve ethically sustainable and, from a societal point of view, acceptable types of innovation, and (2) is enabled by means of organizing an interactive process that involves the opinions and capabilities of various relevant societal actors within the innovation process in an active and timely fashion (cf. Van Oudheusden 2014, pp. 70). The discourse on how to democratize innovation and the practice of trying to democratize science, technology and innovation already have a longstanding and diverse tradition (Stilgoe et al. 2013).

Technology Assessment (TA) as an analytic and democratic practice fits well within this tradition (Von Schomberg 2012). In particular, Parliamentary Technology Assessment, defined as, 'technology assessment specially aimed at informing and contributing to opinion formation of the members of parliament as main clients of the TA activity' (Enzing et al. 2011, pp. i) has played an important role in the discourse on RI that took place before RI existed (cf. Van Est and Brom 2012). ${ }^{1}$ In general, TA involves awareness about potential positive and negative societal effects of technological change, as well as the belief or hope that one can anticipate these effects (cf. Rip 1986). It is broadly defined as 'a scientific, interactive and communicative process, which aims to contribute to the formation of public and political opinion on societal aspects of science and technology' (Bütschi et al. 2004). TA is neither a

1 Across Europe, 'Parliament' refers to a democratically elected political body that has the task of controlling the executive power (the government) on a daily basis. A 'parliament' can also be described as the freely-elected assembly of the people. Different legislative levels may or do have parliaments: nations, regions within nations, and the European Union. 
separate field of scientific research, nor a well-defined practice (Grunwald 2009). Many disciplines - from policy analysis and risk assessment to ethics and cultural studies - have influenced the way TA is understood, institutionalized and performed.

This article introduces and discusses an inclusive way of modelling technology assessment (TA) and, in particular, Parliamentary TA, as developed in the European PACITA project (www.pacitaproject.eu). ${ }^{2}$ PACITA - the 'Parliaments and Civil Society in Technology Assessment’ project - is a joint effort of experienced (P)TA organizations in Europe, paired up with research organizations from European countries in which (P)TA is not (yet) established, but in which an interest can be observed. PACITA studies existing (P)TA practices, but it also studies and acts upon institutional structures that offer opportunities for setting up (P)TA in countries with an interest in it. PACITA operates with the presumption that existing practices can serve as examples for countries and regions in which (P)TA is not (yet) established, but that such models will always have to be adjusted to the local context. PACITA's overall objective is

2 PACITA is one of the European research and action plans that is part of the umbrella organization of the European Union's Seventh Framework Programme for Research (FP7). The project started in April 2011, and will last for four years. The participating (P)TA organizations are: the Danish Board of Technology (DBT, Denmark), the Institute of Technology Assessment and Systems Analysis (ITAS, Germany), the Rathenau Instituut (the Netherlands), the Norwegian Board of Technology (NBT), the Institute of Technology Assessment (ITA, Austria), the Institute Society and Technology (IST, Belgium), the Catalan Foundation for Research and Innovation (FCRI, Spain) and the Swiss Centre for Technology Assessment (TA-SWISS). Research institutes in the consortium of countries in which (P)TA was not (yet) established are: the ARC Fund (Bulgaria), the Institute of Technology of Biology and Chemistry (ITQB, Portugal), the KEF (Lithuania), the Technology Centre ASCR (Czech Republic), the Université de Liège (SPIRAL, Belgium), University College Cork (UCC, Ireland) and the HAS-SEC (Hungary). 
to empower European member states with an interest in (P)TA to make informed decisions about institutionalizing, organizing and performing (P)TA. PACITA is also meant to stimulate reflexivity in regions and countries with established (P)TA organizations. In doing so, PACITA aims to improve the democratic quality of knowledge-based decision making on science, technology and innovation in Europe.

In this article, we model TA as an activity at the interplay among four spheres: parliament, government, science and technology, and society. ${ }^{3}$ TA acts as a mediator among the actors in these spheres, as well as among the knowledge claims of these actors. Actors from each of the above-mentioned spheres are potential clients of TA. If scientists and engineers are the main clients, TA can help guide research and technology development from a societal perspective. Constructive technology assessment (CTA) is a type of TA aimed at influencing technological choices and design processes (Schot and Rip 1997). Policymakers are also potential clients of TA (such as for TA-SWISS and the Austrian ITA, as will be discussed in Section 4.2), and thus a task of TA is also to inform them about the societal aspects of science and technology. TA activities can also be aimed at the general public (cf. Van Eindhoven 1997, Joss and Bellucci 2002) in order to stimulate public debate on science and technology.

This paper is concerned with (P)TA, that kind of technology assessment directed especially at members of parliament. In different European countries, (P)TA is organized in different ways (cf. Enzing et al. 2011, Hennen and Ladikas 2009, Cruz-Castro and SanzMenéndez 2005, Vig and Paschen 2000). Where it exists, (P)TA plays a politically legitimized role in the democratic decision-making processes of the governance of science, technology and innovation in society (Van Est and Brom 2012).

3 In this context, the sphere of 'society' is used as an umbrella term for the spheres of citizens, non-governmental organisations and the media. 
One task of PACITA is to describe and compare current practices of (P)TA in Europe. In particular, researchers investigated (P)TA practice in Austria, Catalonia (Spain), Denmark, Flanders (Belgium), Germany, the Netherlands, Norway and Switzerland. For each country or region, a team consisting of TA practitioners from the respective TA unit and a member of the PACITA project from outside that unit carried out several semi-structured expert interviews with the main actors and stakeholders in the field, in particular, members of parliament and directors of the TA unit. In addition, the teams exploited institutional archives, websites and, in particular, earlier descriptions of the respective institutions (see below) to compile thick and upto-date descriptions and analyses. The reports on all countries have the same setup, clarifying the institutionalization and organization of (P)TA in these countries. Furthermore, one TA project per (P)TA organization was included as an in-depth case study, illustrating the 'nuts and bolts' of daily practice. With these data, the teams elaborated the qualitative input in a common table (see Table 2 below), which has later been transformed into semi-quantitative scores that enable the comparative analysis (for further details see Section 4). In the concluding chapter of the report, the analysis was extended to organizations in Finland, France, Greece, the European Parliament, Italy, the United Kingdom and the United States (PACITA 2012).

To carry out this task, we developed an all-embracing way of modelling (P)TA. This model resulted from several iterative loops of communication among task leaders, the task team and other partners in PACITA. The aim of this article is to report and reflect on this modelling. In section 2 below, we first discuss how (P)TA is classified or labelled in the existing literature. In section 3, we describe our new type of modelling, which we apply in section 4 to existing practices of (P)TA in Europe. We summarize and conclude our analysis in section 5.

\section{A Short History of Classifying Parliamentary TA}

The establishment in 1972 and the closing down in 1995 of the American Office of Technology Assessment (OTA) serve as two important landmarks in the history of (P)TA, since OTA was both the first and the largest organization practicing (P)TA in the world, with an annual budget of over US\$22 million and 190 staff, among them approximately 120 researchers (OTA 1996, 
pp. 29 and 54ff.). ${ }^{4}$ It was about ten to fifteen times bigger than the average contemporary European (P)TA organization. The early establishment and practice of OTA inspired the development of (P)TA in Europe, where the concept was copied and altered in various ways (Vig and Paschen 2000). ${ }^{5}$ While details of how (P)TA organizations became institutionalized can be found elsewhere (PACITA 2012), this article wants to meaningfully capture the diversity in institutionalizing, organizing and doing (P)TA, in order to reflect on current practices and inspire discussions about how to maintain existing practices and establish new ones.

Our way of modelling (P)TA practices builds on categories that can be found in the literature. Although the focus of those efforts is clearly on characterizing (P)TA, every labelling effort touches and/or crosses the often unclear border between Parliamentary TA and other types of TA. We will reflect on this issue at the end of this article, because a more sophisticated insight into the institutional relationship between (P)TA and other types will open up new vistas for establishing new (P)TA practices.

The variety of existing classifications are largely related to two basic dimensions, 'methods' and 'involvement'. Figure 1 reflects the balance between (P)TA as an analytic practice and 'wider thoughts of the democratic control' (Van Eijndhoven 1997, pp. 278) over developments in science, technology and innovation (cf. Van Est and Brom 2012).

[Figure 1 about here]

The methods dimension consists of three types: analysis, interaction and communication (cf. Bütschi et al. 2004). Analysis includes a wide range of approaches, from

4 For reasons of simplicity, OTA is here described as a Parliamentary TA organization. As part of the United States Congress, however, OTA was literally a Congressional TA agency (Herdman and Jensen 1997).

5 See Shiroyama et al. (2009) for a discussion of how OTA inspired TA experiences in Japan. 
desk research to interviewing, typically aimed at sketching out the technological status, the societal issues and the policy options for a development under study. Typically, the in-house expertise of TA staff is complemented with that of external experts. Interaction includes the organization of meetings and discussions and, optionally, explicitly inviting stakeholders or citizens to take part in a project. The TA community has developed a rich understanding (Joss and Bellucci 2002) and also a practical toolbox (Slocum 2003) that enable it to organize such stakeholder and citizen participation, with approaches including focus groups, future panels and consensus conferences. The task of interacting with society is often combined with the task of stimulating public debate and opinion formation, which may be carried out via diverse communicative means: through press releases, media interviews and writing for non-expert audiences. The organization of technology festivals is another way of reaching out to a broad public. Typically, authors do not describe these methods as being alternatives, but rather as additional ways of doing (P)TA. So the methods are stacked up; analysis is always the basis on which actions, aimed at interacting with parties and/or the stimulation of public debate, can be added (cf. Bütschi et al. 2004).

With regards to the involvement dimension (P)TA is, by definition, always somehow related to parliament. But also a whole range of other actors may be included in the process. Experts will almost always be involved, but, in addition to them, stakeholders (such as nongovernmental organizations, consumer organizations or industry) and/or citizens may be included.

In what follows, we discuss various attempts to classify (P)TA practices and institutions on the basis of the dimensions of 'methods' and 'involvement' (see Table 1).

Falkner et al. (1994), Enzing et al. (2011), Hennen and Ladikas (2009) and Cruz-Castro and Sanz-Menéndez (2005) all characterize (P)TA organizations from the perspective of institutionalization. They group (P)TA practices by positioning them closer to or further away from parliament. In addition, they distinguish between TA organizations that only have to serve parliament alone and those that have to serve two types of clients parliament and the broader public. According to these authors, being institutionalized further away from parliament 
generally implies higher involvement levels and a broadening of the types of methods that are used.

[Table 1 about here]

Bütschi et al. (2004) speak of 'scientific organizations' that are typically placed in the realm of the 'experts', somewhat away from parliament, and that use scientific analysis as the dominant method. A 'Parliamentary TA body’ may be positioned closer to parliament, while ‘consultancy agencies' are likely to be more closely attached to a diverse group of stakeholders in society. Finally, 'dialogue platforms' are set up to stimulate debate, by asking scientists, stakeholders and/or citizens for their views on politically relevant themes.

Grin and Hoppe (2000) coin the term 'Participative-Interactive' TA. They believe that this is connected to 'pluriform TA-research capacity'. Mapped on Figure 1, this implies that a plurality of methods is being used and that TA projects are generally characterized by high involvement levels. In addition, they speak of 'Usable’ TA, a 'multiform TA-research capacity', meaning that the range of potential experts that is available for TA studies is broadened from inhouse researchers to hiring researchers from outside the TA organization, whose skills are tailored to expertise needed for the duration of a certain project. This gives a TA organization flexibility, which may contribute to the impact that the TA project has on the political domain.

Petermann (2000) distinguishes a 'Discursive Model', which is characterized by a high level of involvement and the use of a wide set of methods, from an 'Instrumental Model', which in Figure 1 may be positioned at the intersection of 'analysis' and 'experts'. As an additional category, Petermann mentions the 'combination of models'.

Van Eijndhoven (1997) contrasts ‘Public Technology Assessment’, implying high levels of involvement that demand that methods be extended beyond analysis, with the classical (P)TA and OTA 'paradigm'. In the classical paradigm, (P)TA is focused on providing decisionmakers with information on the likely future effects of a technology. Besides analytical studies, 
(European variations on) the OTA scheme also acknowledges the need for stakeholder involvement in order to develop relevant and legitimate policy alternatives for parliament.

Peissl and Torgersen (1996) combine the method dimension with the dimension of organizational set-up. Their 'Classical Concept' refers to the expert-oriented model of the OTA, and thus it coincides with the two first paradigms as described by of Van Eijndhoven (1997), namely the classical (P)TA and OTA paradigm. Their 'Participatory Model', exemplified by the former Danish Board of Technology, places the institutions on the 'involvement' axis of Figure 1. Their 'TA Secretariat Model', however, refers not to involvement or methods, but to how much in-house capacity an institution has to carry out TA projects.

A number of scholars have looked for relationships among the arrival of different concepts for (Parliamentary) TA in various countries and regions. Meyer (1999), for example, argues that (P)TA has broadened from an expert-based, parliament-oriented concept in the USA to concepts in Europe that have opened up to industry, other stakeholders and the public at large. Delvenne et al. (2011) suggest that (P)TA is evolving on an 'overall reflexivity pathway', 'on which some (P)TAs have moved farther than others'. On this pathway, (P)TA has moved away from a mainly analytical activity that is 'aimed at providing decision-makers with an objective analysis of the effects of technology on political agenda, decision-making processes and society as a whole', and has opened up more to plurality and uncertainty, thereby 'acknowledging and responding to the limitations of modern traditions'.

(P)TA can also be interpreted as an element within a much broader evolving landscape of the democratic governance of science, technology and innovation (cf. Rip 2012). Overall developments matter, but local contexts matter even more. Enzing et al. (2011) emphasize the enabling and constraining elements that each and every (P)TA organization encounters within the broader, evolving landscape. They consider the 'path dependencies such as institutional settings and legislative regimes' (Enzing et al. 2011) that organizations face in a specific country or region to be an important variable in explaining the rich diversity of the (P)TA practices we encounter across Europe. 


\section{Development of Inclusive Modelling of (P)TA within the PACITA Project}

Over the last forty years, a substantial variety of European (P)TA organizations not only has developed but, as Enzing et al. (2011, pp. ii) notice, this variety “can be expected [to] be enlarged when new countries will institutionalize (P)TA.” Rather than considering this broad variety a nuisance, we claim that it should be embraced, accounted for and understood. The history of TA in Europe shows that overall trends in establishing TA can be identified, but local contexts matter greatly. Successfully positioning new (P)TA practices in additional countries or regions may depend on variables that lie just outside or even further away from one of the historically developed classifications that have been identified so far.

In developing a more inclusive approach - to account for this variety of TA - we first found that not a lot of improvement was needed with respect to the method dimension, as the literature well-described scientific and participatory methods for (P)TA (cf. Joss and Bellucci 2002, Slocum 2003, Decker and Ladikas 2004, Grunwald 2009 and 2010). In contrast, we found that the dimension of involvement required more elaboration. As shown above, most of the literature has focused on the question of to what extent each (P)TA organization has been set up within or outside the parliament. Moreover, and directly connected to the methods they employed, the (P)TA organizations were typified by the type of actors they involved. Our modelling effort builds on the common knowledge that (P)TA organizations are defined by far more than institutional linkages. For example, it is well known that in various cases the government, in addition to the parliament, also plays a role as client. Moreover, the involvement of actors from various societal domains can take many different forms. Involvement, then, not only refers to being engaged within TA projects, but may also refer to other types of involvement, such as being on the board of the (P)TA organization, being involved in defining the work programme or being involved as a sponsor or an evaluator of the work.

Besides opening up our characterization of (P)TA to multiple types of involvement, we aim to make the manner in which (P)TA is typified more transparent. We must thus clarify which indicators are used in characterizing (P)TA. Moreover, we have asked (P)TA 
practitioners themselves to characterize their own practice by using the various indicators. We believe it is a real advantage when the diversity, encountered in practice, can be traced back in the modelling scheme and does not become hidden again behind renewed classification efforts.

Ultimately, we modelled (P)TA to operate in a complex institutional landscape that consists of four spheres: parliament, government, society, and science and technology (see Figure 2). Depending on the position of the TA organization within this institutional landscape and its task or tasks, the (P)TA organization will aim to influence one or more of the connecting interfaces.

[Figure 2 about here]

First, our modelling incorporates the historically articulated tasks that (P)TA is supposed to perform. From the start, (P)TA has been promoted as scientific support through the timely informing of parliaments about negative social impacts of S\&T (interface 1 in Figure 2). Second, (P)TA is promoted because it may change the balance of power between parliament and government by offering parliamentarians arguments that they can use in their task of controlling the government (interface 2). Third, it is regularly claimed that (P)TA might also play a constructive role in public controversies concerning science and technology, for example, by informing politicians about which scientific and technological developments are likely to be able to count on public support (interface 3). A TA organization that performs (P)TA is supposed to act along at least one of these three interfaces. ${ }^{6}$

6 Ironically, critics of (P)TA focused on the same three interfaces (cf. Van Est \& Brom 2012). The science and technology field regularly depicted TA as technology harassment. It was feared that TA slowed down innovation, because extra bureaucracy was introduced in the political decision-making process (interface 1). Critical social groups feared that TA would become a governmental instrument to push science and technology, which also affects the 
The relevance of the three interfaces is illustrated by the history of the establishment of the US OTA in 1972, and the way the concept was adopted and altered in Europe. OTA challenged the existing relationship among Congress, the Executive branch agencies and science. In the 1960s, the US Congress feared that it had become the 'rubber stamp' of the executive branch of government (with respect to making decisions on science and technology) (Kunkle 1995, Blair 2014: 450). The establishment of a congressional TA bureau was a way to redress the imbalance between the legislature and the executive with regard to technological change (relationship interface 2). Besides, this TA organization strengthened the relationship between Congress and the scientific community (relationship interface 1). Especially in Europe, some of the TA organizations were given the additional task of addressing the wider public (relationship interface 3) with a view to managing public interest in technological issues, for example, regarding nuclear power plants or biotechnology.

In general, our model embraces the idea of interdependence: (P)TA plays a role as mediator among the actors of the different spheres and their knowledge claims. ${ }^{7}$ In contrast, the existing literature highlights the term "independence" virtually a priori taking the formal institutional relationship between the (P)TA organization and parliament as the main factor that determines the 'dependence' or 'independence'. For example, 'Independent', as in the term Independent Institute (Enzing et al. 2011), refers only to the (P)TA organization's relative independence from the parliamentary sphere. But using the word 'independent' in this narrow sense may falsely suggest that the (P)TA institute may be similarly independent from other societal spheres. Our model aims to make transparent the various interdependencies between the

power balance between parliament and government (interface 2). Others feared that TA would diminish the public support for political decisions on innovation (interface 3).

7 (P)TA as mediator between different spheres resonates with the characterisation of the US OTA as “boundary organization”, mediating between science and politics (cf. Bimber 1997, Guston 2000 and Guston 2001). 
(P)TA organization and the above-named spheres, precisely because we assume that these spheres enable and constrain the way (P)TA works in practice and the impact it may have.

A major asset of this perspective is, therefore, that it provides a way to describe and compare (P)TA with other forms of TA in which the formal, institutional relationship to parliament is either non-existing or forms only one type of institutional relationship amongst other (formal) connections with the other three societal spheres. Moreover, our modelling confirms the fact that, as we know from practice, an organization performing (P)TA may also serve other clients. It may optionally influence the relationships between science and society (interface 4), government and science (interface 5), government and society (interface 6) and even combinations of these and/or the previously mentioned three interfaces. The modelling also shows that organizations that perform TA for governments may get the extra task of providing members of parliament with information. In this manner, our model embraces the notion of institutional flexibility. Realizing this variety and flexibility is crucial when thinking about possibilities, or institutional opportunity structures, that exist in countries that have not yet institutionalized (P)TA, but do have a lively TA scene.

\section{Applying the Modelling to Existing (P)TA Organizations}

\subsection{Interaction Mechanisms}

Our modelling is founded on the notion of interaction mechanisms, ${ }^{8}$ loosely defined as procedures or routines on the institutional, organizational and project level for involving different spheres in practising (P)TA. The interaction mechanisms employed by a particular (P)TA organization will depend on its formal tasks, its organizational context and the democratic culture it is part of. Such contextual factors enable and constrain the ways a (P)TA

8 In the report on which this article is based (PACITA 2012), we speak of organizational mechanisms. However, we consider the term interaction mechanism better suited, since the interactions we analyse cut across the institutional, organizational and project levels. 
organization may interact with the outside world. Both formal and informal procedures and routines that have been built up over time are relevant here. Table 2 gives an overview of the interaction mechanisms we discern. This list is also clearly rooted in the existing literature, as discussed in Section 2.

[Table 2 about here]

We discuss, in a comparative fashion, how the interaction mechanisms work out for the various countries and regions we studied. ${ }^{9}$ The client of an organization has a major impact on how it is set up and how its work processes are structured. Some organizations focus solely on parliament (European Parliament: Science and Technology Options Assessment [STOA]; France: L’Office Parlementaire d’Évaluation des Choix Scientifiques et Technologiques [OPECST]; Germany: Büro für Technikfolgen-Abschätzung beim Deutschen Bundestag [TAB]), although they still make their products widely available and support the dialogue between their home institutions and the scientific community, as well as with society at large. Other organizations work for parliament and society (Catalonia and Flanders). We see a combination of parliament, government and society as clients for Denmark, the Netherlands, Norway and Switzerland. Austria is the only organization investigated for which the science community is an explicit client, in addition to clients from the other three spheres.

Funding is also an important category of interest. It may involve long-term basic funding schemes, but also short-term sponsorships on a project level. Exclusive parliamentary funding exists, for instance, STOA, OPECST, TAB and the United Kingdom (Parliamentary Office of Science and Technology [POST]). In Catalonia (Advisory Board of the Parliament of

9 Detailed information for each organization, presented in Table 2, can be found at [URL-A]. That information was retrieved in 2012, except for the information for Finland, which was added to the set in 2013. 
Catalonia for Science and Technology [CAPCIT]) there is sponsorship from the science and technology community. In Austria (Institute of Technology Assessment [ITA]), the Netherlands (Rathenau Instituut) and Switzerland (TA-SWISS), the funding scheme is related to both the governmental and the scientific spheres. We encounter a more dispersed funding pattern in Denmark (from 2012) and Flanders (until 2012), where parliament, science and society are involved.

The evaluation committee or group refers to the group of people with the formal task of examining and reporting on the functioning of the organization as a whole. For organizations that work relatively independently from parliament, this function often manifests as an evaluation committee. This committee may be installed by the government (as happens in the Netherlands, every five years, and in Norway in 2011), or by the organization's 'own' steering committee or board (as happens in Switzerland, where this steering committee consists mainly of representatives of the scientific community), or by an evaluation board set up by the mother institution (like the Austrian Academy of Sciences does for ITA). The Danish Board of Technology uniquely had and still has two boards: a board of governors and a board of representatives. The latter takes an organizational, evaluative stance in annual report meetings. In these organizations, representatives from different societal spheres are involved in the evaluation procedures. For any type of evaluation, clients and additional stakeholders may be interviewed in order to identify the successes and failures and the opportunities and possibilities for improvement. In relation to organizations that work more closely with parliament, it is no surprise that parliamentarians have a stronger say in the evaluation of the organization. This evaluation can be arranged formally, like in Flanders, where the regional parliament installed an evaluation committee upon the proposal of the organization's board. In Germany, too, there is a formal evaluation every three to five years, when parliament decides on the renewal of the contract with a scientific organization that is to operate the TA office for the next period. The STOA panel's performance is evaluated at least once per five-year legislative term by the European Parliament's Vice-President responsible for the STOA panel, who submits his/her evaluation report to the European Parliament's Bureau. In the UK, Catalonia and France, no 
formal evaluation procedures exist (except, indirectly, through general elections). Nevertheless, parliaments in each of these countries may (at any time) decide to change internal procedures and routines that affect the organization, which can be considered as a de facto evaluation. Most of the organizations have a board, committee, panel or platform that has regular interactions (typically about every two to three months) with members of the management team that is in charge of performing daily TA activities. We may consider the practical influence of such an entity somewhere in-between steering and advising, on a strategic level. For the European Parliament and Germany, this entity consists of parliamentarians only. In France, it is the parliamentarians themselves who perform TA, and their staff have an auxiliary function. One commonly finds parliamentarians with a strong background in science among the members of such bodies, as is, for example, the case for the STOA panel. In Austria, ITA's board consists solely of science representatives, and the Steering Committee of TA-SWISS is also strongly linked to the scientific community. In Flanders and Catalonia, the board or panel was and is equally divided between parliamentarians and representatives from the science and technology community. More dispersed patterns of involvement of different spheres exist in other organizations.

Most of the organizations have an annual, bi- or tri-annual working programme, which has the aim of clarifying and prioritizing interesting themes on which the organization should focus. Establishing such a programme is a parliamentarian task for the European Parliament, carried out by the STOA panel, which takes into account requests from both parliamentary committees and individual members. In Germany, this responsibility is shared between politicians and the scientists from the TAB office. At other organizations, we see a stronger involvement from society and government. In addition to internal procedures and routines such as discussions with the board or committee - the draft programmes are often discussed with people from outside the organization, whose advice is incorporated in updated versions. ITA's three-year scientific research programme partly corresponds to the Austrian government's priorities with regard to solicited research projects, and it is therefore indirectly 
checked for its relevance to policymaking. CAPCIT does not work on the basis of a working programme, but priorities are set periodically at each meeting of CAPCIT members.

We use the word staff to refer to the people who are in charge of the TA projects. In principle, these people may have ties to any of the four societal spheres: parliament, government, science and society. In practice, most of the organizations' staff are mainly based in science. The inclusion of more communication and (project) management skills in the organizations accounts for the involvement of the societal sphere in Denmark, Flanders, the Netherlands, Switzerland and Norway. The French situation is unique, because it is the only organization in which parliamentarians themselves carry out this task.

Procedures and routines at the project level open up additional assemblages of involvement. The TA staff may outsource portions of the work. For this reason, the project team is a relevant, additional category, as are project participation methods and mechanisms for project advising and/or reviewing. This advising and/or reviewing role may be rather modest, for example, when it means having scientific peers or stakeholders review draft texts that staff have prepared. The other extreme is a heavy involvement of experts and stakeholders throughout the complete project, as is usually the case in Norway. Overall, the line between advising and reviewing is a thin one, since process and product often co-evolve in TA projects.

\subsection{Relative Involvement of Spheres: Five Models and the Possibility of More}

Our discussion of interaction mechanisms shows the great diversity in the countries and regions studied. None of the (P)TA practices is very similar to any of the others. But for the aim of discussing the future prospects of (P)TA in Europe, within and beyond the aims of the PACITA project, it is fruitful to simplify this assemblage of options into a limited, coherent number of models. By doing so, we are able to connect our more open way of modelling (P)TA to the more restrictive ways of characterizing (P)TA that can be found in the literature reviewed in Section 2.

We allowed for such modelling by asking (P)TA organizations to express the involvement of each of the four spheres in percentages for each of the nine interaction 
mechanisms. For each mechanism, the quantified involvement of the four spheres should add up to 100 per cent. For example, with respect to the working programme, an organization could estimate the involvement of parliament at $30 \%$, with no government involvement ( $0 \%)$, and involvement by both society and science and technology at 35\%. In determining the overall involvement of spheres for the complete organization, the PACITA task team decided to consider each of the nine interaction mechanisms as equally important. For each organization, a graphical representation was created. The thickness of each arrow represents the strength of the involvement of each sphere. ${ }^{10}$

In order to increase the objectivity of this process, several corrective elements were included. The first is a consistency check with an extensive, detailed description for eight of the countries and regions in the comprehensive PACITA (2012) report. The second is the specific approach made to the TA experts, as listed in the Acknowledgements section, to extend the number of organizations covered and also to reflect on draft descriptions and mappings. The third is the self-corrective element: emphasizing the involvement of one sphere will, in terms of the graphical representation that results, automatically happen at the cost of giving less priority to the influence of one or more of the other spheres. This stimulates the responding PTA organizations to set their percentages with care. The fourth is several rounds of feedback from all PACITA partners. ${ }^{11}$

Based on this mapping process, five distinct (P)TA models were identified. These five models differ with respect to the relative involvement of the various societal spheres in performing (P)TA. But within a specific category, differences can also be found. We use

10 The spreadsheets used, converting the scores filled out into graphical representations for each of the (P)TA organizations, can be downloaded from [URL-B].

11 Because the Finnish case was added later (in 2013), it has not been part of feedback loops within the PACITA project. 
illustrations ${ }^{12,13}$ to discuss the existing five interaction models and to show the more nuanced differences within each model.

Model 1. Mainly parliamentary involvement in TA

According to Enzing et al. (2011), (P)TA in France, Italy, Greece and Finland is organized according to the parliamentary committee model. We have not studied the situation in any of these countries at the same level of detail as we have for the others below. Here we briefly reflect on the situation in these countries, based on the literature and the way in which the respective organizations have characterized their own situation (cf. Vig and Paschen 2000, Delvenne 2011, Enzing et al. 2011 and, for Finland, Tiihonen 2011). At present there seem to be no (P)TA activities in either Greece or Italy, and therefore these countries are not presented here. We do include the STOA panel, which is the TA institution of the European Parliament, in our discussion.

[Figure 3 about here]

The French OPECST was the first (P)TA organization in Europe. Of all the (P)TA organizations in Europe, OPECST is 'the one most intimately linked with parliament, because it is the parliamentarians themselves who conduct the assessments' (Van Eijndhoven 1997, pp. 271). Accordingly, OPECST have integrated TA fully into the committee structure of the French parliamentary system. The TA project is carried out by so-called rapporteurs, selected

12 In creating the graphical representations, 'Science' was used as shorthand for 'Science and Technology', for reasons of convenience.

13 The dotted lines in Figures 3 to 7 indicate these cases have not been examined in detail in the PACITA (2012) report. 
from among the members of OPECST and responsible for writing the TA report (Enzing et al. 2011). Rapporteurs can organize hearings and missions in France or abroad. They are assisted by parliamentary civil servants and, if needed, supported by a working group or steering committee consisting of experts from outside the parliament. It can be concluded that the French Parliament has chosen a near maximum level of involvement of the TA process, that is, they control all the organizational mechanisms we identified.

The Finnish Committee for the Future not only deals with new science and technology, but also with broader developments in society. Here, the influence of the scientific community on the work of (P)TA is bigger than in France. Although the MPs steer and the committee's secretariat coordinates TA projects, it is mainly experts from universities, the Academy of Sciences and other scientific networks that contribute to them. The Finish (P)TA institution is thus more dependent upon external expertise. Moreover, the Committee of the Future is in a constant dialogue with government, although government has no formal say regarding its working programme.

Generically speaking, this 'mainly parliamentary involvement in TA' model can also be applied to the STOA panel of the European Parliament. The research is carried out by scientists. The STOA panel works with procurement procedures that are embedded in a framework contract, for which scientific consortia, experienced with TA, can apply on a project-to-project basis (Delvenne 2011). The relatively significant involvement of the European Parliament is related to the fact that STOA projects are procedurally embedded in the parliamentary administration, the project’s 'sponsorship' of individual MEPs and project workshops that involve the STOA members and the external project team. The connection to government, that is, the European Commission, is largely absent. Minor involvement was listed in terms of project participation and advising and/or reviewing projects.

\section{Model 2. Shared parliamentary-science involvement in TA}

For the sake of our argument, it is interesting to note how the organizational set-up of OPECST was discussed before its start (cf. Van Eijndhoven 1997). Inside witnesses remember some of 
their thoughts about an organizational division between two phases: a first phase consisting of an in-depth TA analysis performed by scientists; after this, the parliamentarians would come in to sort out the conclusions drawn up by the scientific experts. According to Van Eijndhoven (1997, pp. 271-272), the French MPs ‘quickly concluded that such a division of labor could not work, because translation of scientific results into policy relevant conclusions is a politically laden activity that requires in-depth knowledge of the issues’. As a result, it was decided that parliamentarians should perform the TA themselves, supported by their staff. One could classify the organizational set-up of OPECST as originally envisaged as shared parliamentary-science involvement in TA.

Other countries came to different conclusions: Our study reveals various ways of organizing such 'shared parliamentary-science control over TA'. Historically speaking, until it was abolished in 1995, the US Office of Technology Assessment (OTA) resembled this model (see, for example, Delvenne 2011). A current example is Germany, which Enzing et al. (2011) typify as a 'Parliamentary Office Model'. In Germany, members of the Bundestag are the exclusive clients of TAB. Nevertheless, the TAB reports are public and hence feed into society, S\&T and governmental spheres. MPs decide about funding and are in charge of the evaluation of the TA unit. They also select the members of the parliamentary steering committee, which consists solely of MPs. Moreover, MPs decide on the topics of the TA studies and whether the results of the TA studies will be accepted as suitable to be used as input to the parliamentary debate. Furthermore, every five years, the parliament has the option to choose another research institute (or group of institutes) to carry out (P)TA. Although the German situation thus resembles the situation in France, there is, however, one crucial difference: the actual TA research is performed by researchers within $\mathrm{TAB}$ - a scientific institute that works closely with but is outside the parliament - and, to a considerable extent, by outside contractors. The German model for organizing TA presents a form of 'shared parliament-science involvement in TA', in which the parliament has a strong voice and the final say.

Catalonia presents another form of 'shared parliamentary-science involvement'. According to Enzing et al. (2011), Catalonia can be characterized, just like Germany, as an 
example of the 'Parliamentary Office or Unit Model'. CAPCIT is attached to the regional parliament, but as a mixed body: half of its eighteen members consist of MPs and the other half of scientists. Moreover, the scientific community sponsors and performs the TA activities. CAPCIT can be seen as a way of institutionalizing the relationship between the Catalan Parliament and the S\&T community.

[Figure 4 about here]

POST, the (P)TA organization in the United Kingdom, though working differently from CAPCIT or TAB in Germany, is another example of 'shared parliamentary-science involvement in TA'. In this case, a scientific unit is placed directly inside parliament and works in close contact with MPs. POST has some ties to society and government as well, although they are small: some governmental representatives are consulted on the draft working programme; occasionally, members of the public request that POST conducts a study, either directly or by approaching a Member of Parliament.

\section{Model 3. Shared parliamentary-science-society involvement in TA}

The way (P)TA in Flanders was organized until the end of 2012 can be characterized as a form of 'shared parliamentary-science-society involvement in TA'. Enzing et al. (2011) typify the IST in Flanders as an Independent TA Institute that is just like the TA organizations in the Netherlands, Norway and Switzerland. According to our model and empirical data, the way TA was organized in Flanders did indeed bear similarities to the situation in other countries, but it also showed clear differences.

[Figure 5 about here]

IST in Flanders was set up as an institute inside the Flemish Parliament. In this sense one could characterize IST as a kind of (P)TA office or unit. But the task of IST was both to 
inform its parliament and to stimulate public debate. Both parliament and science had a large say in the way the institute was run. Parliament funded IST and also installed an evaluation committee, mainly consisting of science representatives. Half of the board consisted of MPs and the other half of scientists. Besides parliament, IST had the wider public as its formal client. IST put a lot of effort into stimulating public debate, by means of participation methods, technology festivals and communication. Therefore, IST had to foster links between the TA organization and society. Typifying (P)TA in Flanders (until 2012) as a form of 'shared parliamentaryscience-society in TA' does justice to the fact that IST had strong links with parliament, with science and with society. ${ }^{14}$

Although the foundational structure of the Danish Board of Technology (DBT), as installed in 2012, differs significantly from that of the Flemish situation in terms of funding, board membership and how project teams are organized, it nevertheless has a similar relative influence of the four spheres. The DBT is a body outside parliament that has many clients, but not government. It has strong ties with the sphere of science and technology and, via its participatory procedures, also with society. In comparison to the situation before 2012 (which is not included in our empirical basis here), the link to parliament became weaker.

\section{Model 4. Shared science-government involvement in TA}

In Austria, we find an example of an organization with an emphasis on science. The involvement of the scientific sphere is mainly shared with the government (both in Austria and at the EU level), which is one of the clients, and the most important sponsor. The mother organization of ITA is the Academy of Sciences, and, together with the scientists of the organization itself, the scientific advisory board has the most important influence on the

14 Note that at present there is no TA institution in Flanders. However, in the French part of Belgium, Wallonia, a law is under consideration that would install a TA organization by 2015. 
organization and the project agenda. The scientists also act as project managers and practitioners and keep the balance between policy consultancy and scientific research. Government, and to a certain extent parliament, fulfils the role of client on a project basis; societal actors may be the members of project advisory boards. More recently, parliament has shown increased interest in TA and the organization has expanded its portfolio considerably towards more involvement of society (via participatory TA projects). In addition, its mother institution and the ministry of Science and Research push the organization towards an intensified relationship with society. So, in the medium term, we observe a slow move from Model 4, 'shared science-government involvement in TA' towards Model 5, 'shared parliamentgovernment-science-society involvement in TA' (see below).

[Figure 6 about here]

Model 5. Shared parliament-government-science-society involvement in TA

There is at least one crucial difference between the situation in Flanders (until 2012) and that in the Netherlands, Norway and Switzerland. The influence of the parliament on these latter TA organizations is far weaker. First, while IST was funded by its parliament, the other three organizations are funded by the government. Moreover, while half of the board members of IST consisted of MPs, active MPs do not participate in the boards of the other three countries. Enzing et al. (2011) thus describe these organizations as 'independent' from their parliaments, but they remain dependent on government, and the label 'independent' is therefore a misleading characterization. Governmental involvement also occurs in the case of the US Government Accountability Office (GAO), which has taken up TA functions, though for that organization, the parliamentary involvement is clearly stronger.

[Figure 7 about here] 
To counterbalance against a government influence that is too direct, the money that is allocated for carrying out TA in the Netherlands, Norway and Switzerland is buffered. It is earmarked for an institution that is closely related to science. Government influence in evaluation procedures for this organizational model may differ, however. In the cases of the Dutch Rathenau Institute and the Norwegian Board of Technology (NBT), the government installs an evaluation committee, consisting of societal, political and science representatives. For TA-SWISS, it is the steering committee itself, consisting of science representatives and stakeholders, that calls for an evaluation, and not the government. But TA-SWISS regularly refers to government, as its mission and budget are submitted to parliament by government every four years. In these three cases, a number of seats on the board, steering committee or advisory committee are reserved for representatives from civil society, in addition to science representatives, who are in a majority. Finally, in all these countries, the government and wider society are included as formal addressees, in addition to the parliament. In its role as client, each parliament has an indirect, but crucial, influence on the way the TA organization functions. Accordingly, we typify this model of organizing TA in the Netherlands, Norway and Switzerland as 'shared parliament-governmental-science-society control'.

\section{Further models and dynamics}

Categorizing the relative involvement of the four societal spheres leads, in theory, to fifteen potential organizational models for (P)TA: a dominant involvement of any one of the four spheres accounts for four models; a shared involvement of mainly three spheres gives four other options; the shared involvement of mainly two spheres leads to an additional six models; and sharing the involvement between the four spheres gives one other model. In principle, it is possible to build connections to parliament for all of the fifteen models. Clearly, the lower the involvement of the parliamentary sphere is, the more difficult it becomes to claim the term Parliamentary TA.

Furthermore, while our modelling is not intended to explain all the dynamics - in particular why parliaments chose to install a new institution (such as currently in Wallonia) or to 
abolish a TA institution (such as in Flanders) or to almost discontinue TA activities (such as in Greece and Italy) - our modelling is open to the mapping of dynamic developments of existing organizations. Categorizing a TA organization as a specific model would not mean that it may not change over time. Current examples of such dynamics are the cases of Denmark and Austria. While Denmark can now be best characterized as a model 3 (shared parliamentaryscience-society involvement in TA), it may have been considered a model 5 ('shared parliamentary-government-science-society involvement in TA') before 2012. Similarly, as noted above, Austria is currently drifting from model 4 ('shared science-government involvement in TA') to model 5 as the Austrian parliament is knitting closer ties with the TA and foresight communities and participatory procedures are gaining importance in ITA's work programme.

\section{Conclusions}

In this article, we introduced an inclusive way of modelling (Parliamentary) Technology Assessment, as developed in the European PACITA project. The existing literature typically takes the formal institutional relationship to parliament as the main determinant for classifying a certain (P)TA organization and comparing it with others. Our modelling incorporates more possible interdependencies between the (P)TA organization and the outside world. We modelled (P)TA as a mediating function among the spheres of parliament, government, science and technology, and society, and we created a representative list of interaction mechanisms that could include (or not) these four spheres in TA. In this manner, characterizing a (P)TA organization can be done in a more inclusive, fine-grained and transparent way.

Characterization of various (P)TA practices in Europe and the USA was done by the TA organizations that were involved. This mapping process identified five interaction models currently in operation: 1) 'mainly parliamentary involvement in TA', model 2) 'shared parliament-science involvement in TA', model 3) 'shared parliament-science-society involvement in TA', model 4) 'shared science-government involvement in TA' and model 5) 
'shared parliament-government-science-society involvement in TA'. These five models partially overlap with and complement the classifications described in the existing literature.

Our open and inclusive approach to characterizing (P)TA also shows that another ten models of (P)TA theoretically exist. This additional reservoir of (P)TA functionality, however, has been greatly overlooked. While the absence of empirical examples of these types may mean that they have no ground in the real world, it is also possible that the focus in existing literature organizations with a formal relationship to parliaments has led to the neglect of other types of TA functionality. Debates about existing and future forms of (P)TA can thus be inspired by both the existing institutes and the ten potential new models.

We trust that our more inclusive way of modelling (P)TA be very helpful in classifying (P)TA functions in countries where Parliamentary TA is not (yet) established. Accordingly, it may be used to map and discuss fruitful evolutionary pathways for (Parliamentary) TA in countries and regions where (P)TA already exists or where the ambassadorship for (P)TA is about to take off.

Since responsible innovation (RI) is all about the "inclusion of new voices in the governance of science and innovation” (Stilgoe et al. 2013: 1571) and the arrangement of a "transparent, interactive process by which societal actors and innovators become mutually responsive to each other” (Von Schomberg 2012) our article may contribute to the discourse on and practice of responsible RI in two ways. First of all, our article presents (P)TA as an institutional and organizational practice which aims to stimulate RI, by involving actors (simultaneously) from different societal spheres. From practice we know it is not easy nor evident to connect different spheres of engagement (Van Est et al. 2012). While PTA activities are sometimes criticized for working in isolation from society and science, activities aimed at engaging actors from the societal and science and technology sphere on their turn are regularly criticised for being isolated from the spheres of parliament and government. Our paper illustrates the need to connect different spheres of engagement and offers insight in different kinds of institutional models of (P)TA that have the aim to engage actors from all societal spheres. 
A second relevant insight for RI is that involvement of actors from various societal spheres requires action and reflection, not only on the project level, but also on the levels of organizations and institutions. In the emerging discourse on RI, the interaction between the project level (how to ‘do' RI in research and innovation) and the institutional level (how to 'strengthen’ such RI) gets attention: to what extent should RI get funding and be embedded in EU research and innovation programs (cf. European Commission 2013), and to what extent aspects of RI should be made compulsory for innovators (ibid.), for instance through codes of conduct (Von Schomberg 2012). We feel that the organizational level of RI is, however, still not well articulated. How should a university, a company or an NGO become organized internally, and how can the scattered set of organizations, involved in research and innovation, become institutionally more aligned, in order to be better equipped for taking RI on-board? It is important, therefore that in the discourse on and practice of RI this organizational level is taken seriously.

\section{References}

Bimber, B., The politics of expertise in Congress. The rise and fall of the Office of Technology Assessment, New York: State University of New York Press, 1996.

Blair, P. D., "Congress's own think tank: Learning from the legacy of the Office of Technology Assessment (1972-95)”, Science and Public Policy 41(2014): 449-457.

Bütschi, D., R. Carius, M. Decker, S. Gram, A. Grunwald, P. Machleidt, S. Steyaert, R. van Est, "The practice of TA; Science, interaction and communication," in Bridges between science, society and policy: Technology assessment - Methods and impacts, ed. M. Decker and M. Ladikas, 13 - 55. Berlin, Heidelberg, New York: Springer, 2004.

Cruz-Castro, L. and L. Sanz-Menéndez, "Politics and institutions: European parliamentary technology assessment,” Technological Forecasting \& Social Change 72 (2005): 429_ 448.

Decker, M. and M. Ladikas (eds), Bridges between Science, Society and Policy. Technology Assessment - Methods and Impacts Berlin, Heidelberg, New York: Springer, 2004.

Delvenne, P., C. Fallon and S. Brunet (2011). "Parliamentary technology assessment institutions as indications of reflexive modernization,” Technology in Society 33 (2011): $36-43$. 
Enzing, C., J. Deuten, M. Rijnders-Nagle and J. van Til, Technology across borders - Exploring Perspectives for pan-european parliamentary Technology Assessment, Brussels: European Parliament, 2011, STOA, http://www.europarl.europa.eu/RegData/etudes/etudes/join/2011/482684/IPOLJOIN_ET\%282011\%29482684_EN.pdf.

European Commission, Options for Strengthening Research and Innovation. Report of the Expert Group on the State of Art in Europe on Responsible Research and Innovation, EU Directorate-General for Research and Innovation, Science in Society, 2013, http://ec.europa.eu/research/science-society/document_library/pdf_06/options-forstrengthening_en.pdf

Falkner, G. Peissl, W. and Torgersen, H., "PTA in Europa: der Vergleich,” in TechnikfolgenAbschätzung in Europa, Forschungsstelle für Technikbewertung, ed. G. Falkner, W. Peissl and H. Torgersen, 166-193, Wien, 1994, http://epub.oeaw.ac.at/ita/itaprojektberichte/d2-2e03.pdf.

Grunwald, A., “Technology Assessment: Concepts and methods,” in Handbook of the Philosophy of Science. Volume 9: Philosophy of Technology and Engineering Sciences, ed. M. Dov, A. Meijers and J. Woods, 1103-1146, 2009.

Grunwald, A., Technikfolgenabschätzung - eine Einführung, $2^{\text {nd }}$ edition, Berlin: edition Sigma, 2010.

Guston, D., Between Politics and Science. Assuring the Integrity and Productivity of Research, Cambridge: Cambridge University Press, 2000

Guston, D., "Boundary Organizations in Environmental Policy and Science: An Introduction,” Science, Technology, \& Human Values, Vol. 26, No. 4, Special Issue: Boundary Organizations in Environmental Policy and Science, pp. 399-408, Autumn, 2001

Hennen, L. and M. Ladikas, "Embedding society in European science and technology policy advice," in Embedding society in science and technology policy - European and Chinese perspectives, ed. M. Ladikas, European Commission, Brussels, 39-64, 2009.

Herdman, R.C. and J.E. Jensen, “The OTA Story: The Agency Perspective,” Technological Forecasting \& Social Change 54 (2\&3) (1997): 131-144.

Joss, S. and S. Bellucci, ed., Participatory Technology Assessment - European Perspectives, Centre for the Study of Democracy (CSD) at University of Westminster in association with TA Swiss, London, 2002.

Kunkle, G.C. (1995). "New challenges or the past revisited? The Office of Technology Assessment in historical context,” Technology in Society 17 (2) (1995): 175-196.

Meyer, R. (1999) “Eine kurze Geschichte der TA-Konzepte”, in TAB-Brief, No. 17, December 1999. 
OTA (Office of Technology Assessment), Annual Report to the Congress: Fiscal Year 1995, published March 1996, http://ota-cdn.fas.org/reports/9600.pdf.

PACITA, ed. J. Ganzevles, Q. van Est et al., TA Practices in Europe, Deliverable 2.2 of the PACITA (Parliaments and Civil Society in Technology Assessment) project, 2012, commissioned by: European Commission, September: PACITA Consortium, http://www.pacitaproject.eu/wp-content/uploads/2013/01/TA-Practices-in-Europefinal.pdf .

Peissl, W. and H. Torgersen, "Internationale Institutionalisierungsformen vonTechnikfolgenAbschätzung - Vorbilder für Österreich?” in Technikfolgenabschätzung in Österreich Entscheidungshilfe in einer komplexen Welt. Beispiele aus der Praxis, ed. G. Tichy, Vienna: Austrian Academy of Sciences Press, 30-66, 1996.

Petermann , P., “Technology Assessment units in the European parliamentary systems,” in Parliaments and technology: The development of Technology Assessment in Europe, ed. N.J. Vig and H. Paschen, 37 -61, New York: State University of New York Press, 2000.

Rip, A., "Controversies as informal technology assessment,” Knowledge: Creation, Diffusion, Utilization, Vol. 8, No. 2 (1986): 349-371.

Rip, A., "Futures of Technology Assessment”, in Der Systemblick auf Innovation. Technikfolgenafschätzung in der Technikgestaltung, ed. M. Decker, A. Grunwald and M. Knapp, 29-39, Berlin: edition sigma, 2012.

Schot, J., and A. Rip, “The past and future of constructive technology assessment,” Technological Forecasting and Social Change 54 (1997): 251-268.

Shiroyama, H. , G. Yoshizawa, M. Matsuo and R. Hatanaka, “Activities without Institutionalization: Limits and Lessons of TA and TA-like Activities in Japan,” 2009 Atlanta Conference Science and Innovation Policy, http://dx.doi.org/10.1109/ACSIP.2009.5367849

Slocum, N., Participatory Methods Toolkit. A practitioner's manual, Brussels: viWTA/King Baudouin Foundation, 2003.

Smits, R. "State of the Art of Technology Assessment in Europe, A Report to the 2nd European Congress on Technology Assessment”, Milan, 14-16 November 1990.

Stilgoe, J., R. Owen and P. Macnaghten, "Developing a framework for responsible innovation,” Research Policy 42 (9) (2013): 1568-1580.

Tiihonen, P., "Revamping the work of the Committee for the Future”, Publication of the Committee of the Future 7/2011, http://web.eduskunta.fi/dman/Document.phx?documentId=yf14511143357746\&cmd=d ownload.

Van Eijndhoven, J., “Technology Assessment: Product or Process?” in Technological Forecasting and Social Change 54 (1997): 269-286. 
Van Est, R., and F. Brom, “Technology assessment: Analytic and democratic practice,” In: Encyclopedia of Applied Ethics: Second Edition, volume 4, ed. R. Chadwick, 306-320, San Diego: Academic Press, 2012.

Van Est, R., B. Walhout, V. Rerimassie, D. Stemerding, and L. Hanssen, “Governance of nanotechnology in the Netherlands: Informing and engaging in different social spheres.” International Journal of Emerging Technologies and Society (iJETS) 10 (2012): 6-26.

Van Oudsheusden, M., "Where are the politics in responsible innovation? European governance, technology assessments, and beyond,” Journal of Responsible Innovation 1 (1) (2014): 67-86.

Vig, N.J. and H. Paschen, ed., Parliaments and technology: The development of Technology Assessment in Europe, New York: State University of New York Press, 2000.

Von Schomberg, R., "Prospects for Technology Assessment in a framework of responsible research and innovation”, in Technikfolgen abschätzen lehren. Bildungspotenziale transdisziplinärer Methoden, ed. M. Dusseldorp and R. Beecroft, Wiesbaden: VS Verlag, 2012. 
Table 1. Existing ways of classifying Parliamentary Technology Assessment

\begin{tabular}{|c|c|c|c|c|c|c|c|c|c|c|c|c|c|c|c|c|}
\hline 蛋 & Models & 疋 & 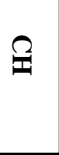 & 畕 & $\underset{ }{\lambda}$ & 团 & 포 & 곡 & 罚 & $\stackrel{\cap}{\not D}$ & $\overline{7}$ & z & ż & 㷁 & $\Xi$ & की \\
\hline 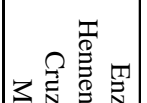 & $\begin{array}{c}\text { Parliamentary Committee model, } \\
\text { Committee model, } \\
\text { Political Parliamentary Office of TA }\end{array}$ & & & & & & $X$ & & $X$ & $X$ & $X$ & & & & & \\
\hline $\begin{array}{ll} & \\
0 & \end{array}$ & $\begin{array}{c}\text { Parliamentary Office model, } \\
\text { Office model, } \\
\text { Technocratic Parliamentary Office of TA }\end{array}$ & $\mathrm{X}^{2}$ & & $\mathrm{X}$ & & $\mathrm{X}$ & & $\mathrm{X}^{3}$ & & & & & & $X^{4}$ & $X$ & \\
\hline 可 & $\begin{array}{l}\text { Independent Institutes model, } \\
\text { Public or interactive model, } \\
\text { Social Parliamentary Office of TA }\end{array}$ & & $X$ & & $X$ & & & $X^{5}$ & & & & $X$ & $X^{6}$ & & & \\
\hline 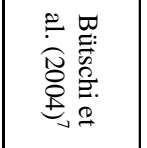 & $\begin{array}{l}\text { Scientific organisation } \\
\text { Parliamentary TA body } \\
\text { Consultancy agencies } \\
\text { Dialogue platforms }\end{array}$ & & & & & & & & & & & & & & & \\
\hline 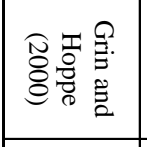 & $\begin{array}{l}\text { Critical-Synoptic: one TA organization } \\
\text { Usable: multiform TA-research capacity } \\
\text { Participative-Interactive: pluriform TA- } \\
\text { research } \\
\end{array}$ & & & & & & & & & & & & & & & $X$ \\
\hline 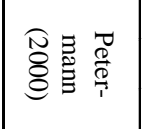 & $\begin{array}{l}\text { Discursive model } \\
\text { Instrumental model } \\
\text { combination of models }\end{array}$ & & & $X$ & $\mathrm{X}$ & $X$ & & & $X$ & & & $X$ & & & $\mathrm{X}$ & \\
\hline 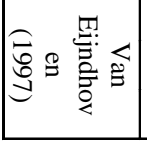 & $\begin{array}{c}\text { OTA paradigm } \\
\text { European variations of the OTA paradigm } \\
\text { Public Technology Assessment }\end{array}$ & & & $\mathrm{X}$ & $\begin{array}{l}X \\
X\end{array}$ & & & & $X$ & & & $\begin{array}{l}\mathrm{X} \\
\mathrm{x}\end{array}$ & & & $X$ & $\mathrm{X}$ \\
\hline
\end{tabular}

${ }^{1} \mathrm{CAT}=$ Catalonia $($ Spain), $\mathrm{CH}=$ Switzerland, DE = Germany, DK = Denmark, EP = European

Parliament, FI = Finland, FL = Flanders (Belgium), FR = France, GR = Greece, $\mathrm{IT}=$ Italy, NL = The Netherlands, $\mathrm{NO}=$ Norway, $\mathrm{SE}=$ Sweden, $\mathrm{UK}=$ United Kingdom, US = United States of America. OTA stands for Office of Technology Assessment.

${ }^{2}$ Catalonia is mentioned in Elzing et al. (2011) only.

${ }^{3}$ Flanders (Belgium) is grouped under the Social Parliamentary Office of TA in Cruz and Sanz (2005)

${ }^{4}$ Sweden is mentioned in Elzing et al. (2011) only.

${ }^{5}$ Flanders (Belgium) is grouped under the Independent Institutes model in Elzing et al. (2011); under Public or interactive model in Hennen and Ladikas (2009).

${ }^{6}$ Norway is not mentioned in Cruz-Castro and Sanz-Menéndez (2005).

${ }^{7}$ No examples of countries or regions were given in Bütschi et al. (2004); only the models were mentioned. 
Table 2. Matrix to indicate which interaction mechanisms and societal spheres are involved in performing (Parliamentary) TA

\begin{tabular}{|c|c|c|c|c|c|}
\hline Level & Interaction Mechanisms & \multicolumn{4}{|c|}{ Relative Involvement of Spheres } \\
\hline & & Parliament & Government & $\begin{array}{c}\text { Science \& } \\
\text { Technology }\end{array}$ & Society \\
\hline Institutional & $\begin{array}{r}\text { Client } \\
\text { Funding } \\
\text { Evaluation of the organization }\end{array}$ & & & & \\
\hline Organizational & $\begin{array}{r}\text { Board, steering committee, } \\
\text { panel or platform } \\
\text { Working programme } \\
\text { Staff }\end{array}$ & & & & \\
\hline Project & $\begin{array}{r}\text { Project team } \\
\text { Project participation } \\
\text { Project advising and/or reviewing }\end{array}$ & & & & \\
\hline
\end{tabular}


[list of figure captions]

Figure 1. Two dimensions which are commonly used in literature to classify practices of (P)TA Figure 2 (Parliamentary) TA between parliament, science and technology, government and society

Figure 3. Instances of Model 1: Mainly parliamentary involvement in TA

Figure 4. Instances of Model 2: Shared parliamentary-science involvement in TA

Figure 5. Instances of Model 3: Shared parliamentary-science-society involvement in TA

Figure 6. Instance of Model 4: Shared science-government involvement in TA

Figure 7. Instances of Model 5: Shared parliament-government-science-society involvement in TA 